\title{
O Leviatã eletrônico: a trama política que colocou o Estado na internet
}

BARRA, Marcello Cavalcanti. O Leviatã eletrônico: a trama política que colocou o Estado na internet. Bauru, SP: Edusc, 2009.

\section{BAFAEL H. MORAES PEREIRA}

\section{Resumo}

As atividades humanas se estão tornando cada vez mais dependentes da internet e, portanto, susceptíveis às suas vulnerabilidades. Entre 1998 e 2002, o governo brasileiro discutiu e implantou a Infraestrutura de Chaves Públicas Brasileira (ICP-Brasil). O objetivo era minimizar a insegurança ao fazer com que a certificação digital, que identifica e autentica pela internet, pudesse operar sobre uma estrutura de criptografia e segurança digital oficial do Estado, com validade jurídica. O livro "O Leviatã Eletrônico: a trama política que colocou o Estado na internet", de Marcello Barra, discute a relação entre Política, Tecnologia e Segurança Digital, ao analisar o processo de criação dessa infraestrutura no Brasil. Com o objetivo de identificar as condições sociais que possibilitaram a efetiva construção da ICP-Brasil, Barra reconstrói os embates técnicos e políticos que precederam esse processo, sem perder de vista a diversidade do conjunto de atores que participaram desse processo. Publicado em 2009, o livro articula a teoria sociológica de diversos autores (como Weber, Elias, Latour, Rosanvallon, Castells, Habermas) para discutir surgimento de uma nova manifestação do Estado (o Estado Eletrônico) e suas implicações no debate acerca da transparência do setor público, da autoridade do Estado e da Segurança Nacional.

Palavras-chave: Estado eletrônico. Governo eletrônico. Internet. Estado. ICP-Brasil.

\footnotetext{
* Técnico de Planejamento e Pesquisa do Ipea - Instituto de Pesquisa Econômica Aplicada.
} 
Em alguns Estados brasileiros já existem leis que obrigam a administração pública dos municípios a disponibilizarem as informações sobre suas despesas e receitas públicas em tempo real na internet. Recentemente, também, alguns tribunais de justiça no Brasil iniciaram a digitalização de seus arquivos e estão trabalhando com tramitação eletrônica de processos judiciais. Nessa mesma onda digital, o Governo Federal vem disponibilizando na internet o detalhamento de obras do Programa de Aceleração do Crescimento (PAC), além de canais de comunicação para monitoramento e denúncia de fraudes do programa Bolsa Família. Além de acessar a divulgação de concursos públicos, licitações e vestibulares, por meio da internet também já é possível fazer apostas na loteria, fazer a declaração do imposto de renda, emitir título de eleitor ou CPF.

Esses são apenas alguns exemplos de como a internet se tem mostrado cada vez mais presente na vida dos brasileiros. Esse crescimento vertiginoso das possibilidades de aplicação prática da internet no cotidiano das pessoas, contudo, levanta questionamentos sobre como o desenvolvimento das atividades humanas se está tornando cada vez mais dependente da internet e, portanto, suscetível às suas vulnerabilidades. Esta questão traz consigo alguns questionamentos sobre a própria garantia de segurança que se presume estar por detrás da utilização da internet.

O livro "O Leviatã Eletrônico", de Marcello Barra, discute a relação entre Política, Tecnologia e Segurança Digital e inicia esse debate com um questionamento: Como acreditar na veracidade de algo na internet? E como ter certeza de que a prestação de contas de um município na internet não foi violada e teve seus valores alterados? Ou como ter segurança de que o processo jurídico que se acompanha no site do tribunal é o mesmo processo que, de fato, passou pela análise do juiz? Como se assegurar de que o resultado de uma licitação ou concurso público/vestibular divulgado na internet não foi violado e teve seu resultado alterado? 
Ainda, como ter segurança de que um depósito bancário será creditado na conta de quem se deseja e não será desviado para outra pessoa por algum hacker?

Em cerca de três anos e meio (entre 1998 e 2002), o Governo Federal brasileiro discutiu e implantou a Infraestrutura de Chaves Públicas Brasileira, a ICP-Brasil. Assim como em outros países, o surgimento de uma ICP oficial visa sanar essas dúvidas, ao fazer com que qualquer certificação digital, identificação ou autenticação pela internet pudesse operar sobre uma mesma estrutura básica de criptografia e segurança digital oficial do Estado e ter validade jurídica.

O processo de criação dessa infraestrutura, bem como de sua implementação no Brasil e o debate que a precedeu constitui justamente o objeto de pesquisa abordado em "O Leviatã Eletrônico - a trama política que colocou o Estado na internet", publicado pela EDUSC em 2009. O livro faz uma leitura desse processo com o objetivo de identificar as condições sociais que possibilitaram a efetiva construção da ICP-Brasil. Sem perder de vista a diversidade do conjunto de atores que trabalharam nessa construção, bem como a complexa rede de inter-relações que se construíram em seus discursos, o livro costura a trama por detrás da construção da ICP-Brasil com o corpo teórico e conceitual de alguns autores de referência para a Sociologia, como Weber, Elias, Latour, Rosanvallon, Castells, Habermas, entre outros.

Ao analisar os discursos dos diversos atores que participaram da construção da ICP-Brasil, o livro aponta um conjunto de temas e embates que estavam presentes na gênese do Estado Eletrônico, tais como déficit democrático, captura da política por interesses empresariais, etc. Como destacou seu autor, a noção de path dependence ("dependência do caminho"11), segundo a qual as alternativas de ação e decisão de uma instituição de-

1 Cf. BARRA, 2009, p. 35. 
pendem do caminho por ela percorrido, antecipa o alerta de que essas questões poderão persistir, demandando futura atenção das autoridades públicas. O livro de Barra explora esse caminho discutindo surgimento dessa nova manifestação do Estado por meio do Estado Eletrônico (expresso pela ICP-Brasil) e suas implicações no debate acerca da transparência do setor público, do controle do Estado e da Segurança Nacional.

A Infraestrutura de Chaves Públicas Brasileira (ICP-Brasil) é constituída por algumas instituições dos setores público e privado, além de um conjunto de regulamentos e normas técnicas. Uma das principais funções da ICP-Brasil constitui em garantir a autenticidade, a integridade e a validade jurídica de documentos e transações em formato eletrônico. Em larga medida, essa função é desempenhada por suas atividades de regulamentação, fiscalização e suporte às atividades de certificação digital no país. Por meio da certificação digital é possível, entre outras coisas, garantir o sigilo e a privacidade de transações na internet ou gerar a assinatura eletrônica de formulários e de mensagens preenchidos pela web, que teriam a mesma validade jurídica de uma assinatura feita a punho.

Embora poucas pessoas tenham conhecimento da existência dessa Infraestrutura, ela se faz muito presente no cotidiano das pessoas. Por exemplo, operações envolvidas com o Sistema de Pagamentos Brasileiro (SPB), como uma simples compra no cartão de crédito ou uma operação bancária de transferência eletrônica (como o TED) possuem sua segurança construída sobre a Infraestrutura de Chaves Públicas brasileira. Para se ter uma dimensão de sua importância, segundo o Banco Central do Brasil (2004), a soma das transferências financeiras feitas com o auxílio da ICPBrasil, no ano de 2004 girava em torno de $\mathrm{R} \$ 180$ trilhões $^{2}$.

2 BANCO Central do Brasil. Dados estatísticos. Sistemas de Pagamentos Brasileiro. [2005]. Disponível em: <http://www.bcb.gov.br/pom/spb/estatistica/port/estatisticas.pdf >. Acesso em: 17 jan. 2006. apud. BARRA, 2009, p. 26. 
Na ponta desta Infraestrutura podem estar (1) cidadãos e instituições que, ao navegarem na internet beneficiam-se de alguma proteção, mesmo sem saber, como o caso de acessos a sites de gerenciamento de conta bancária; ou (2) cidadãos e instituições que consomem diretamente os serviços de certificação digital, por exemplo, com a compra de um e-CPF ou um e-CNPJ. Como mediadores nessa Infraestrutura estão as Autoridades Certificadoras (ACs) de primeiro e segundo nível, empresas e instituições que prestam os serviços de autenticação, certificação ou identificação digital.

No topo desta Infraestrutura está a Autoridade Certificadora Raiz (AC Raiz) ligada ao Comitê Gestor da ICP-Brasil que, por sua vez, encontra-se ligado à Casa Civil da Presidência da República. O Comitê Gestor possui um série de responsabilidades, tais como estabelecer a política, os critérios e as normas técnicas para o credenciamento das ACs, estabelecer as diretrizes e as normas técnicas para a formulação de políticas de certificados e regras operacionais, mapear políticas externas, bem como realizar acordos de cooperação internacional, promover a atualização tecnológica do sistema e garantir sua conformidade com as políticas de segurança.

No Brasil, o Instituto Nacional de Tecnologia da Informação (ITI ${ }^{3}$ é a Autoridade Certificadora Raiz, cujas atribuições incluem a fiscalização e auditoria das ACs, bem como a execução das Políticas de Certificados, pela implementação das normas técnicas e operacionais aprovadas pelo Comitê Gestor da ICP-Brasil. Noutras palavras, a ICP-Brasil cria uma base comum de diálogo para as normas e técnicas operacionais de segurança digital.

Além disso, essa Autoridade Certificadora Raiz constitui a primeira autoridade da cadeia de certificação digital. A Autoridade Certificadora Raiz cria as condições básicas para que seja possível assegurar a identidade de um usuário ou a autenticidade de um documento em mídia eletrônica,

3 Uma autarquia pública federal. 
por meio das normas técnicas operadas pelo ITI e por meio dessa estrutura primeira de códigos criptográficos que ele emite (conhecida como "Certificado Raiz"). Assim, é a segurança sobre essas condições que garantem a validade do reconhecimento jurídico e legal das assinaturas digitais.

Nesses termos, uma das teses centrais que Marcello Barra suscita em seu livro é a de que o surgimento da Infraestrutura de Chaves Públicas brasileira num contexto das políticas de governo eletrônico (e-gov) constitui um marco para se repensar o papel do Estado e sua capacidade de atender os cidadãos pela internet. Não por acaso, aponta o autor, a estrutura de chaves públicas constitui o conjunto de tecnologias que mais foi objeto de regulamentação do governo eletrônico nos últimos anos.

A pesquisa por detrás do livro teve, como uma das suas principais fontes, a legislação específica sobre o tema da certificação digital. A metodologia utilizada envolveu ainda a análise de uma extensa lista de documentos técnicos e o conteúdo dos discursos obtidos de 24 entrevistas semi-estruturadas realizadas com pessoas que pertenceram ao $1^{\circ}$ Comitê Gestor e comitê técnico do processo de criação da ICP-Brasil. Entre os entrevistados estavam membros da academia, burocracia do governo federal, funcionários de empresas privadas e do setor financeiro, membros da $\mathrm{OAB}$, políticos do Executivo, além de representantes da indústria de tecnologia da informação. Assim, ao investigar as condições sociais que possibilitaram a efetiva construção da ICP-Brasil, o livro faz uma leitura desse processo, tendo em vista a diversidade do conjunto de atores que participaram dessa construção, bem como a complexa rede de inter-relações que se construíram em seus discursos e interesses.

A análise sistemática empregada sobre o conjunto dos documentos e discursos daqueles atores envolvidos na construção da ICP-Brasil oportunizaram ao autor apontar as condições sociais que teriam possibilitado a efetiva construção da infraestrutura de chaves públicas brasileiras, classificando-as em três dimensões não estanques. 
Barra destaca inicialmente as precondições sociocognitivas, onde inclui o acúmulo de conhecimento jurídico. Esse conhecimento atuou como ponte entre a tecnologia (capaz de promover a identificação e a autenticação digital) e a política (onde o Estado atribui reconhecimento jurídico legal à certificação digital). Isso envolveu esforço, tanto por parte dos advogados em compreender alguns aspectos técnicos da certificação digital, quanto de engenheiros, em compreender seus aspectos jurídicos, além de um estudo de direito comparado com as legislações de cerca de 66 países.

Dentro dessa dimensão, o autor também ressalta o domínio da língua inglesa, que apontaria para uma internacionalização da burocracia do Estado e a acumulação de conhecimentos tecnocientíficos. Esse acúmulo teria sido possível mediante a existência de um conjunto de normas internacionais que orientam regulamentação da Infraestrutura e que foram adequadas à legislação brasileira e mediante a escolha de um sistema computacional para a certificação digital.

Sobre este último ponto, o autor destaca ainda que o processo de assimilação da tecnologia para infraestrutura de chaves públicas pelo Brasil (no âmbito da segurança digital em pleno século 21) deu-se da mesma maneira que a incorporação de novas técnicas se havia dado pelo país durante o século $19^{4}$. Segundo Gilberto Freyre, essa incorporação trataria de um processo de importação de novas tecnologias, aprendizado de sua produção e produção de uma tecnologia nacional própria.

No grupo de condições socioeconômicas Barra destaca a participação direta da Federação Brasileira de Bancos (Febraban) na construção da ICP-Brasil. A partir de 2001, o novo Acordo de Capital feito pelo comitê de Basiléia apontava novas normas do sistema bancário internacional onde se incluía a utilização de sistemas de certificação digital. Esse con-

4 Cf. Barra, 2009, p. 63-64. 
texto histórico somado a um emaranhado de relações pessoais e institucionais entre políticos do Executivo e membros do setor financeiro teriam garantido uma participação mais direta da Febraban na construção da infraestrutura de chaves públicas brasileira.

Antes da Febraban ser inserida de fato no processo de construção da infraestrutura de chaves públicas brasileira, havia uma posição predominante - ainda que não consensual - entre os técnicos da burocracia favorável à construção de uma infraestrutura de chaves públicas governamental, que daria suporte à segurança digital nas operações realizadas estritamente dentro do Estado. A inserção do setor financeiro nos debates alterou o jogo de forças e, por fim, optou-se pela construção de uma infraestrutura de chaves públicas que valesse para operações de certificação digital no país com valor para o Estado, estivessem envolvidos agentes públicos ou privados. A não entrada da Febraban no debate da ICP-Brasil, portanto, teria levado à construção de uma outra organização de infraestrutura de chaves públicas no Brasil, que não a consolidação da atual infraestrutura brasileira e do mercado de certificação digital.

Segundo Barra, a criação da ICP-Brasil teria sido favorável aos bancos, na medida em que, diante de uma crescente demanda por serviços na internet, uma parcela da segurança digital utilizada pelos bancos, assim como uma parcela dos custos que essa segurança implica, estariam sendo assumidos pelo Estado, por meio da própria construção e operação da ICP-Brasil. Neste ponto, Marcello indica que esta seria uma manifestação daquilo que Celso Furtado chamou de "socialização dos prejuízos" e privatização dos benefícios ${ }^{5}$.

Esse e outros desdobramentos da entrada da Febraban no tabuleiro político da construção da ICP-Brasil suscitam o alto grau de permeabili-

5 FURTADO, Celso. Formação econômica do Brasil. Brasília: Universidade de Brasília, 1963, apud BARRA, 2009, p.75. 
dade existente entre as esferas econômica e política. A análise de Barra revela como o setor financeiro que, em princípio, seria um ator eminentemente econômico, entra num campo de disputa política e adere ao jogo, por assim dizer, de recrutamento de "aliados e simpatizantes" ${ }^{16} \mathrm{Com}$ intuito de fazer valer o seus interesses. Nas palavras de Barra:

os bancos estiveram orientados pela política, pelo ator político e pelos processos políticos. Isso evidencia a interdependência de precondições e condição sociopolíticas e precondição socioeconômica para o caso da Infraestrutura. (BARRA, 2009, p. 76)

As condições de natureza sociopolítica que Barra aponta para o surgimento da ICP-Brasil são a Razão de Estado, o Estado Relacional e o Estado Instituidor do Social. O autor identifica no conceito de "Razão de Estado", de Swergio Pistone a principal condição sociopolítica para o surgimento da ICP-Brasil. Segundo Pistone, a "Razão de Estado" seria definida pela subordinação que qualquer outro valor teria à necessidade da segurança externa do Estado ${ }^{7}$. Nesse ponto, Barra joga luz sobre uma conexão entre esse conceito de Razão de Estado presente em Pistone e aquilo que Rosanvallon denomina por "Estado Leviatã", cuja primeira razão de ser é "[...] assegurar a paz civil e a coexistência pacífica das diferenças - [que] reencontra uma nova atualidade ${ }^{\prime \prime}$.

À medida que retoma o conceito de "Estado Leviatã" em Rosanvallon, identifica-se, no livro de Barra um paralelo à teoria do Estado de

6 WEBER, Max. Parlamento e governo na Alemanha reordenada: crítica política do funcionalismo e da natureza dos partidos. Petrópolis: Editora Vozes, 1993., apud BARRA 2009, p.182. 7 PISTONE, Swergio. Razão de Estado. In: BOBBIO, Norberto; MATTEUCCI, Nicola; PASQUINO, Gianfranco. Dicionário de política. 5. ed. Brasília; São Paulo: EdUnB; Imprensa Oficial do Estado de São Paulo, 2004. p. 1066-1071. v. 2. Passim. apud BARRA, 2009, p.84.

8 ROSANVALLON, Pierre. "O Estado em movimento", Sociedade e Estado, Brasília, v. 6, n. 2, p. 9-18, jul.-dez. 1991.. p. 16 apud BARRA, 2009, p.86. 
Max Weber ${ }^{9}$. Para este autor a característica inerente e diferenciadora dos Estados Modernos é o monopólio legítimo da força. A análise de Marcello Barra permite identificar uma versão contemporânea desse monopólio. Diante da possibilidade de a Internet fugir ao controle da sociedade, Barra escreve que o Estado Leviatã retomou seu papel de garantidor da segurança, por meio da monopolização, em última instância, do registro e da certificação digital no Brasil. Noutras palavras, a instituição da Infraestrutura de chaves públicas brasileiras convergiu com aquilo que Barra identifica como uma retomada, por parte do Estado, do seu papel primeiro, remodelandose enquanto Leviatã Eletrônico. Ao investigar as condições que possibilitaram o surgimento da ICP-Brasil, portanto, "O Leviatã Eletrônico" representa o reposicionamento da relação Estado e Sociedade e da própria relação entre os Estados Nacionais no contexto da era da informação.

Sobre este ponto, em particular, o livro destaca o conceito "Estado Relacional", de Norbert Elias, como uma das condições sociopolíticas para o surgimento da ICP-Brasil. Assim como, para Elias, a tensão entre os Estados nacionais em torno de questões de segurança e paz estaria relacionada à formação e à coalizão daqueles Estados, ao longo dos séculos, para Marcello Barra, a vulnerabilidade desses Estados perante a incapacidade de controle sobre a rede mundial de computadores (seus fluxos de dados e informações), a partir do sec. XIX, ascendeu uma nova questão de segurança nacional, relacionada à segurança digital. A cooperação internacional pela interoperabilidade dos sistemas de certificação digital de diversos países surge, então, como meio de combater essa situação de insegurança.

Como afirma Barra, a notável interdependência dos Estados nacionais faz com que a questão da segurança em geral e a questão da seguran-

9 WEBER, Max. Economia e sociedade: fundamentos da sociologia compreensiva. Brasília; São Paulo: EdUnB; Imprensa Oficial do Estado de São Paulo, 2004. p. 525. v. II. 
ça digital em particular, seja, cada vez mais, uma questão decidida entre os Estados ${ }^{10}$. Nesse ponto, embora o autor concorde com Castells (1999) quando este afirma que a globalização intensificaria a interdependência dos Estados Nacionais, que passariam a ter uma soberania compartilhada sobre suas principais questões, Barra destaca que a emergência de um Estado Relacional (materializado nos acordos de cooperação com outros Estados, pelo intercâmbio de conhecimentos jurídicos e tecnocientíficos e na análise da experiência de 66 países no campo de certificação digital) foi condição sine qua non para existência da ICP-Brasil ${ }^{11}$.

Ainda, o livro explicita como o papel de Instituidor do Social, desempenhado pelo Estado brasileiro em diferentes momentos, foi essencial para o surgimento da ICP-Brasil. Barra deixa claro que a atividade de certificação com fins comerciais já existia no país antes da instituição da infraestrutura de chaves-públicas brasileira e que esse mercado de cerificação digital tendia ao monopólio da empresa Certisign ${ }^{12}$. Foi nesse contexto, em meio às incertezas do mercado de certificação digital no país e em meio a inúmeros interesses (do segmento financeiro, da academia, do setor público e da sociedade civil), que o Estado interveio no sentido de instituir uma nova ordem no setor de certificação digital.

As condições que Barra aponta como decisivas para o surgimento da ICP-Brasil foram suscitadas pela análise do conjunto dos discursos captados nas entrevistas. Diversas questões apreendidas na análise são apresentadas ao longo dos capítulos centrais do livro e expõem uma riqueza de detalhes nos discursos dos entrevistados e nas relações que se constroem entre os atores envolvidos.

10 Cf. BARRA, 2009, p.46.

11 Cf. BARRA, 2009, p.90.

12 Uma empresa privada nacional associada, no capital e na tecnologia, a uma norte-americana, a VeriSign. Cf. BARRA, 2009, p.95-96. 
Além de identificar diversos tipos de dominação weberiana operando nas interações entre os atores, o livro identifica cisões dentro de grupos de atores, explicitando as contradições e o caráter multifacetado dos setores que participaram do processo de construção da ICP-Brasil. Barra dá destaque àquilo que Elias chamou de "ambivalência fundamental das relações sociais", particularmente nas relações que se construíram entre políticos e burocratas, o que o autor chama de "alianças e desalianças" entre a técnica e a política.

Fundamentalmente, Barra identifica, na fala dos atores, diversos pontos de disputa, mas também de cooperação. Por um lado, políticos assumiam o direcionamento geral do projeto e se viam como representantes da sociedade, legitimados pelo voto. Por outro, a burocracia se creditava o grupo social preparado e preposto pela sociedade para conduzir o projeto, pois esta se achava detentora da neutralidade do conhecimento técnico necessário para construção operacional da infraestrutura e carregaria consigo a defesa do interesse público por ser permanente no corpo do Estado ${ }^{13}$.

No decorrer do processo de construção da ICP, contudo, o político necessitou compreender a técnica, e o técnico precisou compreender a política, evidenciando-se uma mistura de papéis onde se desmascarou o papel técnico da política e o papel político da técnica. Nessa questão, o autor destaca dois atores que desempenharam papéis fundamentais ao personificarem essa interface entre técnica e política. Esses atores foram denominados de técnicoconector e político-conector. Ao fim e ao cabo, essa complexa relação entre técnica, conhecimento e poder teria proporcionado benefícios mútuos para a técnica e para a política. Nas palavras de Barra:

Em algum grau, a técnica recorreu à política para se viabilizar e a política utilizou a técnica com o objetivo de assegurar o poder. A política viabilizou a técnica, ao social-

13 Cf. BARRA, 2009, p. 177. 
mente legitimá-la por meio da legislação. E a técnica ajudou a viabilizar a política, ao legitimá-la socialmente, quando auxiliou o aumento do controle sobre a máquina do Estado por intermédio de novas tecnologias. [...] Em poucas palavras, a relação entre técnicos e políticos foi de mão dupla: a técnica 'empoderou' a política e a política 'empoderou' a técnica. (BARRA, 2009, p. 138.)

Por um lado, ao regulamentar a questão da segurança digital e instituir uma infraestrutra de chaves públicas brasileira, o Estado contribui de maneira definitiva para o avanço da tecnologia dando um passo importante para construção de um mercado de certificação digital no país. Por outro, o desenvolvimento e a aplicação da tecnologia por detrás da certificação digital expandiu a atuação do Estado para além das fronteiras que, até então, balizavam as teorias do Estado Moderno, presente em autores clássicos como Rousseau, Hobbes, Montesquieu ou os Federalistas. Neste ponto, o livro revela uma relação simbiótica em que o Estado favorece um avanço no desenvolvimento tecnológico e a tecnologia proporciona uma ampliação no escopo de atuação do Estado.

Em determinados momentos, o livro sugere uma revisão da própria construção da Democracia na relação entre Estado e Sociedade intermediada pelo meio eletrônico virtual, no sentido de se adaptarem as regras do jogo democrático a esse novo meio de interação. Em tese, a informatização do Estado teria o potencial de proporcionar maior transparência na utilização dos recursos públicos, que poderiam ser mais bem fiscalizados pela sociedade. Na prática, a desigualdade no acesso à internet e a exclusão digital que ora se observam no país apontam a importância de políticas promotoras da universalização do acesso à rede, no sentido de aumentar a transparência e a permeabilidade do Estado pela internet e fortalecer a democracia.

Já no prefácio do livro, Fernanda Sobral, professora de Sociologia da Universidade de Brasília, levanta outro questionamento sobre a relação en- 
tre Estado Eletrônico e democracia. Ela questiona como uma tecnologia como a ICP-Brasil poderia contribuir ao mesmo tempo para a segurança e para a democratização da sociedade. Paradoxalmente, embora a infraestrutra de chaves públicas surja "no espírito da democratização e da transparência pública" o domínio e o exercício dessa tecnologia pelo Estado desempenha papel chave para a questão da segurança nacional e amplia sua capacidade de vigilância sobre o comportamento dos indivíduos na web.

O livro permite ao leitor questionar como poderia esperar-se uma atuação democrática dessa nova face do Estado, o Leviatã Eletrônico, tendo em vista que seu próprio processo de formação não fluiu por meios claramente democráticos. Embora a pesquisa de Barra aponte que diferentes grupos sociais se tenham utilizado de espaços públicos (como a imprensa e a Internet) para manifestar suas críticas à ICP-Brasil, o autor também identifica inúmeras características que põem em dúvida o caráter democrático do processo de formação da infraestrutura de chaves públicas. Segundo o autor, houve um esvaziamento da participação do Congresso Nacional no processo de construção da ICP-Brasil e não houve debate amplo com a sociedade sobre o processo de transformação da ICP-Gov em ICP-Brasil. Os representantes da sociedade civil foram pessoalmente nomeados pelo chefe de Estado e não seriam representativos da maior parte dos atores que tinham reais interesses acerca do assunto (BARRA, 2009, p. 190). Embora tenham sido realizadas duas consultas públicas, estas foram realizadas posteriormente às decisões finais tomadas pelos políticos do Executivo.

Barra sugere que, em certa medida, a própria maneira como a questão da ICP-Brasil foi levada para a sociedade, contribuiu para explicar a baixa repercussão pública do tema. Mesmo tratando-se de uma questão com implicações sobre o cotidiano da população (como questões de privacidade, relações entre clientes e bancos, etc.), desinteressava ao próprio Estado que houvesse uma maior participação social no debate do 
tema, na medida em que havia uma forte vinculação da infraestrutura de chaves públicas a uma questão eminentemente de segurança nacional (BARRA, 2009, p. 106).

Sob este aspecto, o autor deixa claro como a utilização da Internet pelo Estado e a própria inserção do Estado na internet por meio da ICP-Brasil, ao se vincular a uma questão de segurança nacional, transcende o surgimento apenas de um governo eletrônico. Configurou-se, sobretudo, no surgimento de um e-Estado (BARRA, 2009, p. 200). Nas palavras do autor:

O Leviatã buscou, antes de tudo, assegurar a existência do próprio Estado, o que resultou, com o caso da ICP-Brasil, no aumento da centralização do poder. Como garantidor da segurança, buscava diminuir a insegurança na Internet, ao possibilitar mais segurança no uso de sistemas de informática que fossem conjugados à rede [...] (BARRA, 2009, p. 172).

Ao investigar as condições que possibilitaram o surgimento da ICPBrasil, portanto, o livro "O Leviatã Eletrônico" investiga também as condições que permitiram o surgimento do Estado Eletrônico e consiste numa importante contribuição do estudo sobre o reposicionamento da relação entre os Estados Nacionais e da própria relação entre Estado e Sociedade no contexto atual.

Se cada vez menos a segurança nacional é tratada como um assunto puramente doméstico, em que medida essa crescente interdependência na esfera internacional não aponta para a constituição de Estados supranacionais no longo prazo? Que espaço existiria para a efetiva participação da sociedade civil na Política de Segurança de Informação e na Política de Defesa Nacional, em meio ao processo histórico recente de aumento da participação social na gestão governamental?

O surgimento do Leviatã eletrônico nos leva a revisitar o pensamento clássico sobre o papel do Estado Moderno e, ao mesmo tempo, lançar um olhar para o futuro questionando como as relações sociais e econômi- 
cas operadas na internet poderão ser mediadas por essa nova dimensão do Leviatã eletrônico. Como o avanço da democracia e fortalecimento das instituições pode ser construído num ambiente virtual, aproveitandose das tecnologias da informação de maneira libertária sem, contudo, ser autoritária e sem comprometer a segurança?

\section{The Electronic Leviathan: the political plot to the raising of electronic State}

\section{Abstract}

\section{BARRA, Marcello Cavalcanti. O Leviatã eletrônico: a trama política que colocou o Estado na internet. Bauru, SP: Edusc, 2009.}

Human activities are becoming increasingly dependent on the Internet and, therefore, susceptible to its vulnerabilities. Between 1998 and 2002, the Brazilian government discussed and implemented the ICP-Brasil or, the Brazilian Public Key Infrastructure (Infra-estrutura de Chaves Públicas do Brasil). The aim was to minimize the uncertainty by providing a digital certification - to identify and authenticate in the Internet - that could work with the State's official structure of cryptography and digital security, with legal value. Marcello Barra's book "O Leviatã eletrônico: a trama política que colocou o Estado na internet" (The Electronic Leviathan: the political plot to the raising of electronic State) discusses the relationship between Politics, Technology and Digital Security in the analysis of the development of this infrastructure in Brazil. To identify the social conditions that enabled the effective development of the ICP-Brasil, Barra recreates the technical and political clashes that preceded this process, without losing sight of the diversity of actors who participated in the process. Published in 2009, the book articulates the sociological theory of several authors (such as Weber, Elias, Latour, Rosanvallon, Castells, Habermas) to discuss the emergence of a new manifestation of the State (the electronic State) and its implications in the debate on the transparency of the public sector, the authority of the State and the National Security.

Keywords: Electronic State. Electronic government. Internet. State. ICP-Brasil. 


\section{Referências}

CASTELLS, Manuel. A sociedade em rede. São Paulo: Paz e Terra, 1999.

BARRA, Marcello Cavalcanti. O Leviatã eletrônico: a trama política que colocou o Estado na internet. Bauru, SP: Edusc, 2009.

HOBBES, Thomas. Leviatã ou matéria, forma e poder de um Estado eclesiástico e civil. São Paulo: Nova Cultural, 1999.

Recebido: 12/11/2009

Aceite final: 03/03/2010 